\title{
The importance of health professionals communication for patient safety: narrative review
}

\begin{abstract}
The research allowed identifying the relationship between communication between health professionals and patient safety in a hospital environment. It enabled us to identify the opportunities found to promote safety in the institution, demonstrating that communication permeates all activities that integrate patient care. Therefore, a precise communication is required between members of the sectoral and intersectorial team, being the foundation of the relations, as well as an essential element to the practice of human care, integral and reduced damages to the patient.
\end{abstract}

\author{
Volume 4 Issue 2 - 2017 \\ Hilaine Cristina Batistini, Camila Bianchini, \\ Isabela Cristina de Oliveira, Eliane da Silva \\ Grazziano, Regimar Carla Machado \\ Federal University of São Carlos (UFSCar), Brazil
}

Correspondence: Regimar Carla Machado, Federal University of São Carlos, Brazil, Email regimarmachado@gmail.com

Received: August 12, 2017| Published: November 01, 2017

\section{Introduction}

Concern about the quality of care provided and the search for safe care permeate the history and have been a worldwide concern. Currently, patient safety has been the focus of discussion at the national and international levels, due to its importance for health systems and society. ${ }^{1,2}$ These discussions about patient safety and communication are recent and for many years were seen as a utopia. The World Health Organization (WHO) defines patient safety as reducing the risk of unnecessary harm associated with health care to the least acceptable level. ${ }^{3}$ The contributing human factor associated with the greatest number of adverse events is lack of communication. The communication failure can be between the professional and the patient; among professionals of the same professional category, as well as among professionals in a multiprofessional team. It is important to highlight the exhaustion factor (Burnout) that affects health professionals, especially nurses and. ${ }^{4}$ Communication permeates all activities that integrate patient care. The more specialized the service, the greater the need for technical, specialized and accurate information. Ineffective communication is among the root causes of more than $70 \%$ of errors in health care. Interruptions in communication or lack of teamwork are factors that contribute to the occurrence of adverse events and unsatisfactory treatment outcomes. Among the consequences of communication failures are patient harm, increased hospitalization time, and inefficient use of resources. ${ }^{1,5}$ In view of the above, this mini review aimed to identify the relationship between communication between health professionals and patient safety in a hospital environment.

\section{Development}

The safety of the patient was the subject of greater relevance between the studies and synthetically showed that poor communication among health professionals whether it be for language barriers or even for lack of ability can have consequences for the client who is often completely confident in the care provided. ${ }^{1,2,6}$ Effective communication also corroborates a decrease in conflicts in the hospital environment, because when done in a clear and concise manner can bring harmony to the environment, favoring professional interaction. ${ }^{5-7}$ Study emphasized that communication in the nursepatient relationship has three purposes, information, encouragement, participation and interaction. However, by collecting data from the study and in the face of the authors' discussion, it was observed that in general, nurses do not perform any of the three purposes satisfactorily, which impairs the effectiveness of a holistic care. ${ }^{5}$ The reduction of stress was also a presented outcome and showed benefits in the studies found, showing that poor communication has a bad influence on the work environment and can harm the professional leading to stress and even burnout syndrome known as professional exhaustion. ${ }^{8}$

Studies found in this review have demonstrated that training courses and/or continuing education actions in the field of communication skills are effective for improving communication among health professionals and among patients' professionals and patients/family members, which improves quality of the assistance provided and the satisfaction of professionals with their own work environment, thus favoring patient safety. ${ }^{9,10}$

\section{Conclusion}

In addition to patient safety, effective interprofessional communication brings the reduction of conflicts in which it was one of the main outcomes found in the studies of this review. Therefore, the study demonstrates that for effective and safe development of care, communication deserves to be accurate both among sectoral and intersectoral team members, being the foundation of relationships, as well as an essential element in the practice of integral human care And reduced harm to the patient.

\section{Acknowledgements}

None.

\section{Conflicts of interest}

The author declares no conflict of interest.

\section{References}

1. Casey A, Wallis A. Effective communication: principle of nursing practice E. Nurs Stand. 2011;25(32):35-37.

2. Roque KE, Melo ECP. Evaluation of adverse drug events in the hospital context. Esc Anna Nery. 2012;16(1):121-127.

3. World Health Organization. World Alliance for Patient Safety; 2012. 
4. Zanatta AB, Lucca SR. Prevalence of Burnout syndrome in health professionals of an onco-hematological pediatric hospital. Rev ESC Enferm USP. 2015;49(2):253-260.

5. Manojlovich M, Harrod M, Holtz B, et al. The use of multiple qualitative methods to characterize communication events between physicians and nurses. Health Commun. 2015;30(1):61-69.

6. Massoco ECP, Melleiro MM. Communication and patient safety: perception of the nursing staff of a teaching hospital. Rev Min Enferm. 2015;19(2):187-191

7. Klee K, Latta L, Davis-Kirsch S, Pecchia M. Using continuous process improvement methodology to standardize nursing handoff communication. J Pediatr Nurs. 2012;27(2):168-173.
8. Andolhe R, Barbosa RL, Oliveira EM, et al. Stress, coping and burnout among Intensive Care Unit nursing staff: associated factors. Rev ESC Enferm USP. 2015;49:58-64.

9. Freitag M, Carroll VS. Handoff communication: using failure modes and effects analysis to improve the transition in care process. Qual Manag Health Care. 2011;20(2):103-109.

10. Mc Caffrey R, Hayes RM, Cassell A, et al. The effect of an educational programme on attitudes of nurses and medical residents towards the benefits of positive communication and collaboration. J Adv Nurs 2012;68(2):293-301 